\title{
Insulin level and insulin sensitivity indices among healthy children and adolescents
}

\author{
María G. Ballerini, Biochemist ${ }^{a}$ Ignacio Bergadá, M.D. , María E. Rodríguez, Biochemist ${ }^{a}$, \\ Ana Keselman, M.D. ${ }^{a}$, Viviana S. Bengolea, M.D. ${ }^{b}$, Viviana Pipman, M.D. ${ }^{c}$, \\ Horacio M. Domené, M.D. ${ }^{a}$, Héctor G. Jasper, M.D. ${ }^{a}$ and María G. Ropelato, M.D. ${ }^{a}$
}

a. Center for

Endocrinological

Research (Centro

de Investigaciones

Endocrinológicas,

CEDIE) "Dr. César

Bergadá", National

Scientific and Technical

Research Council

(Consejo Nacional

de Investigaciones

Científicas y Técnicas,

CONICET), Pediatric

Endocrinology

Foundation

(Fundación de

Endocrinología Infantil,

FEI), Department

of Pediatric

Endocrinology of

Hospital de Niños

Dr. Ricardo Gutiérrez.

b. Department of

Pediatrics of Hospital

Fernández.

c. Department of

Pediatrics of Hospital

Tornú.

Autonomous City

of Buenos Aires,

Argentina.

E-mail address:

María G. Ballerini,

Biochemist:

mgballerini@cedie.org.ar

Funding:

This study was conducted with the

support of a grant

awarded by the Health

Research Council of the

Government of the City

of Buenos Aires to María

G. Ballerini, Biochemist, and María G. Ropelato,

M.D., and grant PICT

2010-1916/CONICET

awarded to Héctor G.

Jasper, M.D., and María

G. Ropelato, M.D., in

their character as project leaders.

\section{Conflict of interest: \\ None.}

Received: 10-25-2015

Accepted: 04-06-2016

\section{ABSTRACT}

Introduction. Information on insulin reference values and insulin sensitivity indices in the field of pediatrics is scarce.

Objective. To describe insulin range and insulin sensitivity surrogate indices during childhood. Population and methods. Fasting insulin level range and surrogate indices, such as the homeostasis model assessment of insulin resistance (HOMA-IR), among healthy children and adolescents by age, body mass index, pubertal stage (PS), insulin-like growth factor-1 (IGF-1), total cholesterol, and triglycerides.

Results. Two hundred and twenty-six healthy children and adolescents (1-18 years old) were included. Insulin increased with age, body mass index, pubertal stage, IGF-1 and triglyceride levels $\left(r^{2}=0.38, p<0.0001\right)$. Prepubertal children $>7.5$ years old had higher insulin levels [median (P3 and P97) $\mu \mathrm{IU} / \mathrm{mL}$ : 5.0 (1.7-9.6)] than prepubertal children $\leq 7.5$ years old $[2.9 \mu \mathrm{IU} /$ $\mathrm{mL}$ (1.3-10.9), $p<0.01]$. During puberty (from PS II to PS V), insulin was higher in girls than in boys [7.4 (1.8-16.9) versus 5.8 (1.8-12.9), $p<0.01]$. The HOMA-IR index increased in the group of prepubertal children $>7.5$ years old: 1.1 (0.32.0 ) versus children $\leq 7.5$ years old: 0.6 ( $0.3-1.4$, $p<0.01)$. The insulin level and HOMA-IR results were higher in pubertal children compared to the prepubertal group $(p<0.001)$.

Conclusions. Known physiological changes were observed in both insulin levels and the HOMA-IR index among children and adolescents. A fasting blood insulin level of $10 \mu \mathrm{IU} / \mathrm{mL}$ in prepubertal children and of $17 \mu \mathrm{IU} / \mathrm{mL}$ and $13 \mu \mathrm{IU} / \mathrm{mL}$ in pubertal girls and boys, respectively, may be considered as an acceptable cut-off value in healthy children. A HOMA-IR value $>2.0$ and $>2.6$ in prepubertal and pubertal children, respectively, may be considered a warning sign for pediatricians to further investigate insulin resistance.

Key words: pediatrics, insulin, reference ranges, insulin resistance.

http:/ /dx.doi.org/10.5546/aap.2016.eng.329

\section{INTRODUCTION}

The incidence of type 2 diabetes (DM2) is increasing and, according to data published by the World Health Organization (WHO), the risk of diabetes in children has also risen. ${ }^{1}$ Obesity is associated with hyperinsulinism and insulin resistance, which over time will probably result in glucose intolerance and DM. ${ }^{2}$ Kelly et al. demonstrated, in Latin American overweight children, impaired $\beta$-cell function. ${ }^{3}$ Bergman's minimal model and the hyperinsulinemiceuglycemic and hyperglycemic clamp methods are gold standards for the assessment of insulin sensitivity, but they are considered invasive in pediatric practice. ${ }^{4-6}$ Alternatively, surrogate indices or simplified estimations of insulin sensitivity and insulin resistance have been proposed. These are the result of mathematical calculations using fasting or post-stimulus blood glucose and insulin levels in the oral glucose tolerance test..$^{6-8}$ These indices have been validated in pediatrics and provide information similar to reference methods in physiological and pathological circumstances. 8,9 However, methods used in lab tests to measure insulin levels are provided by laboratories that do not indicate reference intervals (RIs) for the pediatric population, therefore limiting the interpretation of insulin results in children and adolescents. ${ }^{10}$ As a consequence, it is necessary that laboratories specialized in pediatric endocrinology collaborate with establishing insulin RIs for the method they use.

Insulin sensitivity decreases with puberty. ${ }^{11,12}$ Increased insulin secretion during this stage has been explained, 
in part, by the increase in body mass index (BMI), sex steroids, the growth hormone (GH) system, and insulin-like growth factor-1 (IGF-1) ${ }^{11,12}$ but the effect of sex has been controversial. ${ }^{8,13,14}$ Insulin resistance is also associated with dyslipemias, specially an increase in triglyceride levels. ${ }^{15}$ Considering that insulin resistance may be present even before a fasting hyperglycemia status is established, ${ }^{2}$ it is important to assess insulin sensitivity and insulin resistance in the pediatric population with adequate RIs, especially in the follow-up of children with risk factors for DM2.

The objective of this study is to describe variations in fasting insulin levels and the glycemia/insulin (G/Ins) ratio, the homeostasis model assessment of insulin resistance (HOMAIR) index, and the quantitative insulin sensitivity check index (QUICKI) using clinical, auxological, and biochemical markers of growth hormone action and lipid profile among healthy children and adolescents in order to establish pediatric RIs.

\section{POPULATION AND METHODS}

A cross-sectional, descriptive study was conducted in healthy children and adolescents aged 1 to 18 years old in the 2010-2014 period. Inclusion criteria: term newborn infants, no history of low birth weight, normal body proportions, height between the $3^{\text {rd }}$ and $97^{\text {th }}$ percentiles, $90 \%-110 \%$ weight-for-height, normal physical exam, adequate calorie intake, no known clinical condition at the time of the study, physical development according to their age. ${ }^{16}$ Children and adolescents taking medications at the time of the study were excluded. Healthy children and adolescents in this study had been assigned to a control group in another clinical trial that also included idiopathic short stature patients to study variants in the IGFALS gene. ${ }^{17} \mathrm{BMI}$ was assessed as per Cole et al., and pubertal stage (PS) as per Tanner. ${ }^{18-20}$ The prepubertal group was categorized by age, into early childhood (children younger than 5 years old) and older than 5 years old, and the latter were sub-divided into two groups according to their median chronological age ( 8.0 years old) to assess insulin sensitivity changes during prepuberty. ${ }^{21,22}$

The sample size was estimated at 147 children and adolescents (http://apps.who.int/iris/ handle/10665/37589), considering an insulin inter-individual biological variability of $58.3 \%$ (https://www.westgard.com/ biodatabase3. $\mathrm{htm})$, a $95 \%$ confidence, and a $\pm 8 \%$ absolute accuracy. The study protocol was approved by the Teaching and Research Committee and the Ethics Research Committee of Hospital de Niños Dr. Ricardo Gutiérrez and the corresponding committees of Hospital Fernández and Hospital Tornú, from the Autonomous City of Buenos Aires. Parents, tutors, or legal representatives gave their informed consent after having received the corresponding oral and written information, and children and adolescents older than 8 years old gave their assent.

Serum insulin was measured within 12 hours of fasting using two methods. The first method was a chemiluminescent immunoassay (InsQML; IMMULITE $^{\circledR} 2000$, Siemens) during the first two study years. Then the methodology of the Endocrinology lab of Hospital de Niños Dr. Ricardo Gutiérrez was changed and the electrochemiluminescence immunoassay method (Ins-ECLIA; Cobas e411, Roche) was introduced. Both methods have been standardized against the $\mathrm{WHO}$ reference preparation (NIBSC, $1^{\text {st }}$ IRP $66 / 304$ standard). Currently, at our lab, the InsECLIA method is used, so to establish RIs for a single method, the Ins-QML and Ins-ECLIA methods were compared using 109 fresh sera (different than the sera of the children and adolescents included in this study) using a ratioplot analysis and Passing-Bablok regression. ${ }^{22}$ The ratio-plot analysis showed that $97 \%$ of relations between the Ins-ECLIA and the InsQML were within the estimated 95\% prediction interval $(1.27 \pm 0.91)$ but no dose effect was observed in the assessed insulin range $(p=0.17)$. As per the Passing-Bablok regression, the InsECLIA measurement is $30 \%$ more accurate than the Ins-QML method, with a constant negative bias of $0.8 \mu \mathrm{IU} / \mathrm{mL}$. The following equation was established, which had been used to correct insulin levels obtained in advance using the InsQML method: ${ }^{23}$ Ins-ECLIA $(\mu \mathrm{IU} / \mathrm{mL})=1.30 \mathrm{x}$ Ins-QML $(\mu \mathrm{IU} / \mathrm{mL})$ - 0.8. Insulin levels following mathematical correction were verified using the EP-28 protocol recommended by the Clinical and Laboratory Standards Institute Guidelines (http://clsi.org/). Inter-assay and intra-assay percent coefficients of variation $(\mathrm{CV} \%)$ were $<4 \%$ using the Ins-ECLIA method. The manufacturer recommends, in the kit annex, an insulin reference interval of 2.6-24.9 $\mu \mathrm{IU} / \mathrm{mL}$, but does not specify age, sex, or pubertal development.

Glucose, total cholesterol and triglyceride levels were established using the Roche Hitachi 912 equipment $(\mathrm{CV} \% \leq 5 \%)$.

To assess insulin sensitivity, the following 
ratios were estimated: $\mathrm{G} / \mathrm{Ins}[\mathrm{G}(\mathrm{mg} / \mathrm{dL})$ and Ins $(\mu \mathrm{IU} / \mathrm{mL})$ ], HOMA-IR [Ins $(\mu \mathrm{IU} / \mathrm{mL}) \mathrm{x}$ $\mathrm{G}(\mathrm{mmol} / \mathrm{L}) / 22.5]$, and QUICKI [1/(log Ins $(\mu \mathrm{IU} /$ $\mathrm{mL})+\log \mathrm{G}(\mathrm{mg} / \mathrm{dL})]$. The $3^{\text {rd }}$ percentile was established as the minimum expected level for healthy children and adolescents when using the $\mathrm{G} / \mathrm{Ins}$ ratio. The $97^{\text {th }}$ percentile was used as the maximum desirable value for the other indices.

Insulin level and ratios were expressed as a standard deviation score (SDS). A multiple correlation was used to identify outcome measures associated with insulin variation while the Kruskal-Wallis test, to assess BMI, insulin, and index variations by PS in either boys or girls. Median and SDS range were compared for insulin and surrogate insulin sensitivity indices at the lower (Q1) and upper (Q4) quartiles of cholesterol and triglyceride levels, and for IGF1 using the Mann-Whitney test. In all cases, a value of $p<0.05$ was considered a statistically significant difference.

\section{RESULTS}

The study included 122 girls and 104 boys grouped by sex and PS into prepubertal (PS I), in turn sub-grouped into three age ranges, and pubertal (PS II-III, IV, and V). Clinical, auxological and insulin level parameters are described in Table 1.

Serum insulin increased in association with age, BMI, PS, IGF-1 level, and triglyceride level $\left(\mathrm{r}^{2}=0.38, p<0.0001\right)$. In the prepubertal group, a positive association between insulin level and age was observed, with no changes in BMI (Figure 1). Based on this observation, children in PS I were re-analyzed based on the median chronological age of the overall PS I group. Results indicated that children $>7.5$ years old had higher insulin levels than those $\leq 7.5$ years old [median and (P3-P97 range) 5.0 (1.7-9.6) $\mu \mathrm{U} / \mathrm{mL}$ versus 2.9 (1.3-10.9) $\mu \mathrm{U} /$ $\mathrm{mL}, p<0.01$ ] (Figure 1.B). Increased insulin levels observed in older prepubertal children was not accompanied by changes in BMI (Figure 1.A). Table 2 shows insulin RIs in the study groups. For the prepubertal group especially, two RI ranges were established by age: younger and older than 7.5 years old. It was observed that insulin was always higher among pubertal children than prepubertal groups. Although a higher insulin level was observed at the onset of clinical puberty (PS II-III), no significant changes were observed during puberty in either girls or boys $(p=0.56$ and $p=0.88$, respectively). Insulin level was higher in the overall group of girls compared to boys [6.0 (1.3-17.8) $\mu \mathrm{U} / \mathrm{mL}$ versus 4.6 (1.8-15.2) $\mu \mathrm{U} / \mathrm{mL}$, $p<0.05]$. Based on PS, girls in late puberty (PS IV and PS V) had a significantly higher insulin level than boys (Table 1 and Figure 1.B). Table 2 shows the RIs established for the pubertal group, for both girls and boys.

The G/Ins ratio, HOMA-IR index, and QUICKI varied with puberty $(p<0.0001$, Figure 2 ). The HOMA-IR was the only index that showed changes in insulin sensitivity during the prepuberty period, with higher levels observed in the group of children $>7.5$ years old. The G/Ins ratio and the

TABLE 1: Clinical characteristics and fasting insulin level in 226 health children and adolescents

\begin{tabular}{lccccc}
\hline & $\mathbf{n}$ & Age (years old) & Height SDS & BMI $\left(\mathbf{k g} / \mathbf{m}^{2}\right)$ & Insulin $(\boldsymbol{\mu I U} / \mathbf{m L})$ \\
\hline Girls & & & & & \\
PS I a & 16 & $3.2 \pm 1.1$ & $0.1 \pm 1.1$ & $16.1(14.1-18.1)$ & $2.9(1.6-6.4)$ \\
PS I b & 23 & $6.6 \pm 0.9$ & $0.4 \pm 1.1$ & $16.4(14.1-18.2)$ & $2.8(1.7-7.9)$ \\
PS I c & 23 & $9.3 \pm 1.1$ & $0.0 \pm 0.7$ & $16.8(14.2-19.8)$ & $4.5(1.7-8.9)$ \\
PS II-III & 19 & $10.9 \pm 0.9$ & $0.6 \pm 1.0$ & $17.6(14.9-20.9)$ & $6.7(1.8-11.9)$ \\
PS IV & 33 & $13.9 \pm 1.6$ & $0.2 \pm 0.8$ & $19.8(16.5-24.0)$ & $7.5(2.5-16.9)$ \\
PS V & 8 & $15.3 \pm 1.3$ & $0.3 \pm 1.3$ & $20.8(17.6-26.3)$ & $7.8(3.8-12.7)$ \\
Varones & & & & & \\
PS I a & 14 & $2.8 \pm 1.1$ & $0.4 \pm 0.9$ & $15.9(14.7-17.2)$ & $2.9(1.3-5.8)$ \\
PS I b & 23 & $6.5 \pm 0.9$ & $0.3 \pm 1.0$ & $16.1(14.2-18.3)$ & $2.8(1.8-12.6)$ \\
PS I c & 23 & $10.1 \pm 1.4$ & $0.1 \pm 1.0$ & $16.6(14.5-20.3)$ & $5.3(1.8-9.7)$ \\
PS II-III & 15 & $12.3 \pm 1.3$ & $0.0 \pm 1.2$ & $18.7(16.4-22.8)$ & $6.6(2.6-13.1)$ \\
PS IV & 10 & $13.8 \pm 1.2$ & $0.8 \pm 1.4$ & $19.3(17.7-24.3)$ & $6.0(2.3-7.6)^{*}$ \\
PS V & 19 & $14.9 \pm 1.4$ & $0.6 \pm 1.3$ & $20.3(17.1-22.8)$ & $5.2(1.8-12.8)^{*}$ \\
\hline
\end{tabular}

Clinical data and insulin levels in healthy boys and girls are described by pubertal stage (PS) and sex.

Age and height standard deviation scores are expressed as mean and standard deviation (SD);

body mass index (BMI) and insulin data are indicated as median and percentile range 3-97. ${ }^{*} \mathrm{p}<0.05$ versus girls at the same PS. 
HOMA-IR index showed higher levels among girls in late puberty versus boys in a similar PS. Table 2 shows the pediatric RIs for the G/Ins ratio, HOMA-IR index, and QUICKI.

For the association between lipid markers and markers of GH action and insulin sensitivity in these healthy children, insulin and surrogate index values were expressed as SDS (using the RIs obtained in this study) to correct variations in age, sex, and PS. Children with high triglycerides (upper quartile: Q4) had statistically higher insulin SDSs (mean \pm SD: $0.2 \pm 1.2$ ) and HOMAIR SDSs $(0.4 \pm 1.5)$, and lower G/Ins values $(0.0 \pm 0.9)$ compared to values obtained at Q1 (insulin: $-0.3 \pm 0.8$, HOMA-IR: $-0.2 \pm 0.9$, G/Ins: $0.4 \pm 1.1, p<0.05)$. Similarly, children with an IGF-1 SDS at the Q4 had higher insulin SDSs $(0.1 \pm 0.8$ versus $-0.4 \pm 0.8, p<0.001)$ and HOMA-

FIGURE 1: Variation in body mass index $(A)$ and fasting insulin level (B) by chronological age, pubertal stage, and sex among 226 healthy children

A

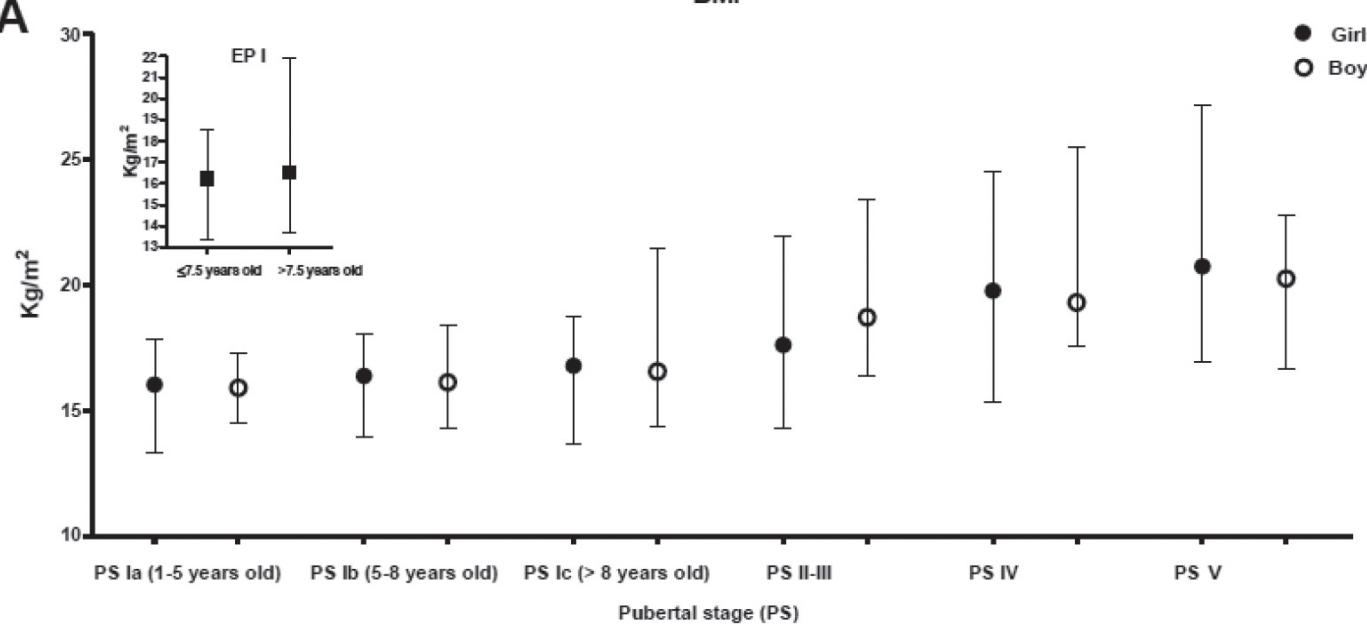

B

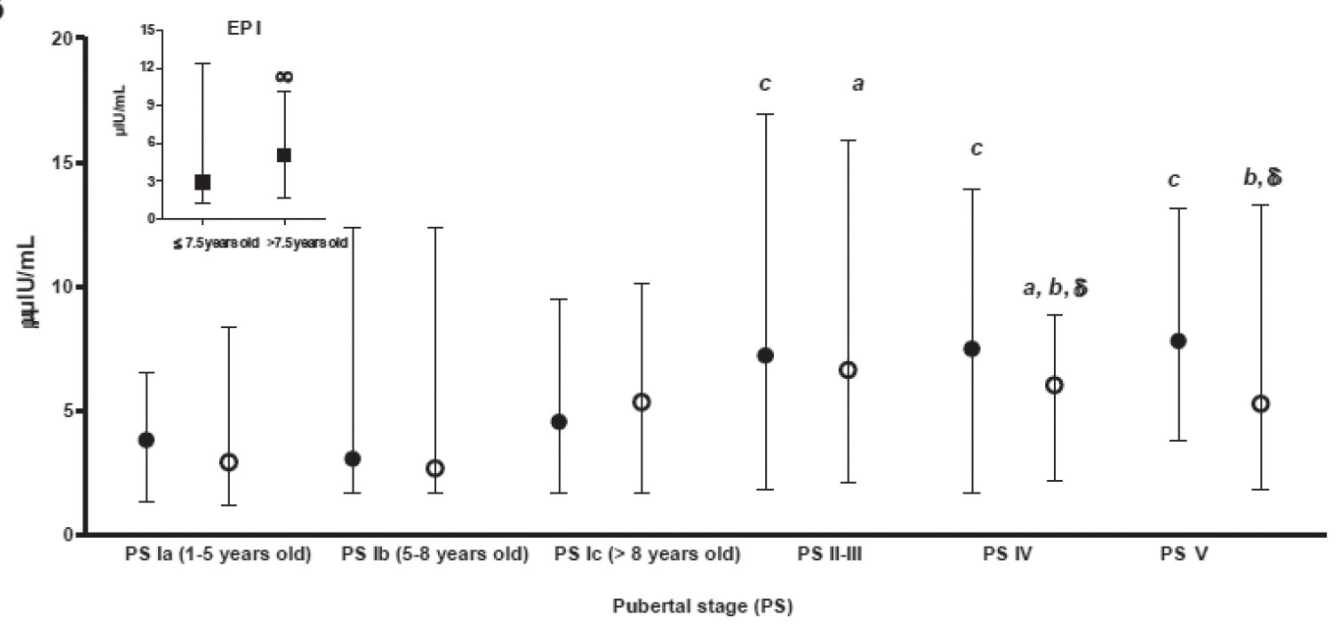

BMI: body mass index; PS: pubertal stage.

The figure shows body mass index and insulin level corresponding to the prepubertal group (PS I), sub-grouped according to their median chronological age (7.5 years old). Data are described as median and lower and upper range for each group. $\mathrm{a}: \mathrm{p}<0.05$ versus PS Ia and PS Ib; b: $\mathrm{p}<0.05$ versus PS Ia; $\mathrm{c}$ p $<0.001$ versus PS Ia, Ib, and Ic; boys versus girls at the same PS. Annex figure: $\infty=\mathrm{p}<0.01$ versus PS I $\leq 7.5$ years old. 
FIGURE 2: Variation in G/Ins ratio (A), HOMA-IR index (B), and QUICKI (C) by chronological age, pubertal stage, and sex among 226 healthy children and adolescents

A

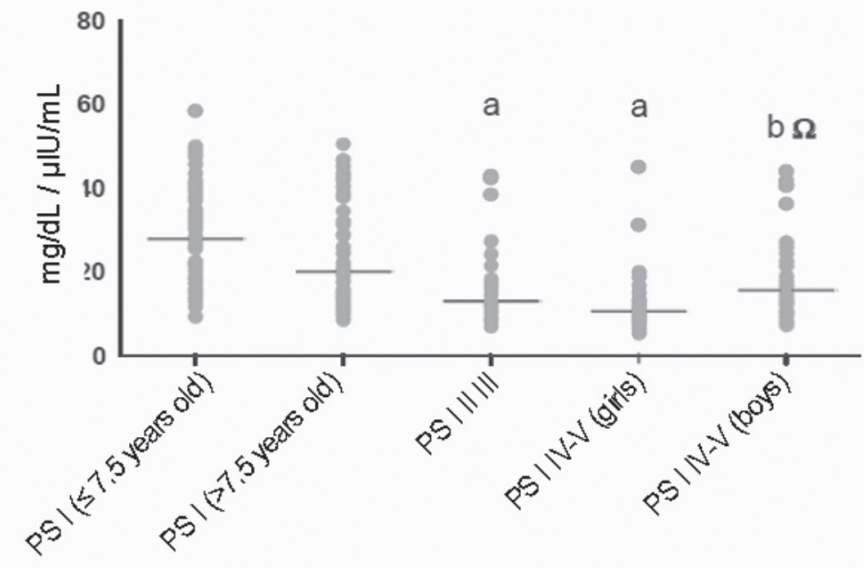

B

HOMA-IR

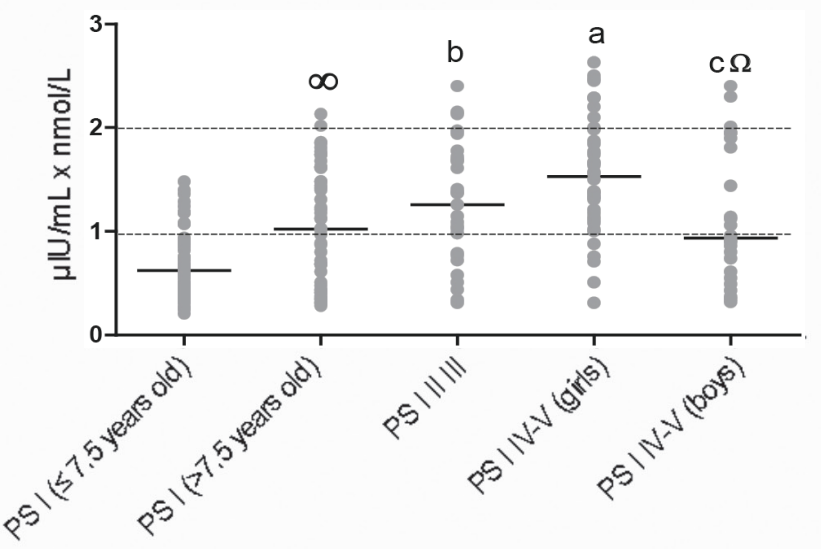

C

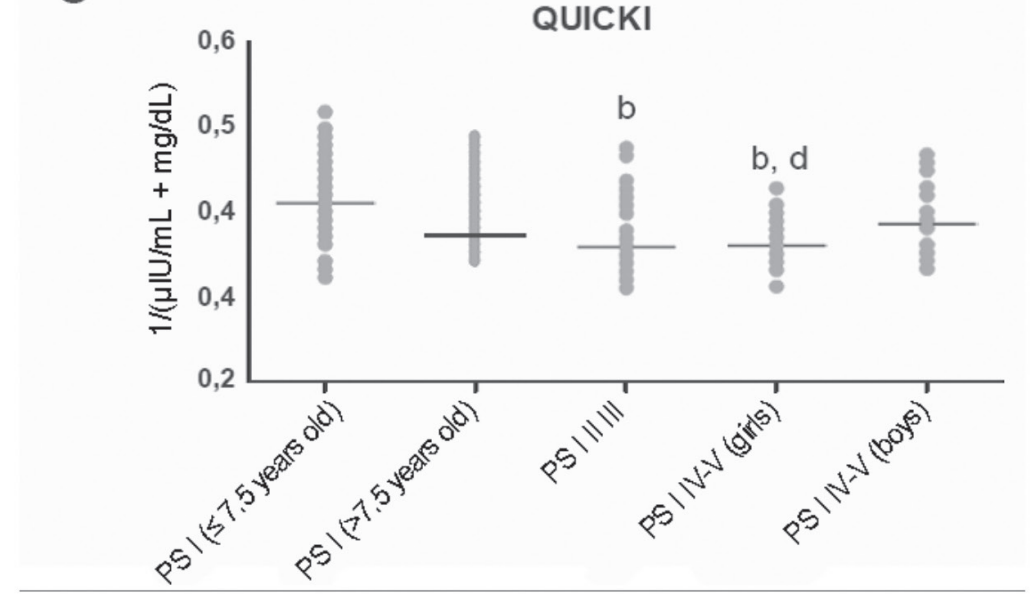

G/Ins: glycemia/insulin ratio; PS: pubertal sate; HOMA-IR: homeostasis model assessment of insulin resistance; QUICKI: quantitative insulin sensitivity check index.

Dots indicate individual data for each studied child, and the horizontal line, the group's median value.

a: $\mathrm{p}<0.001$ versus PS I; $\mathrm{b}$ : $\mathrm{p}<0.01$ versus PS I $\leq 7.5$ years old; $\mathrm{c}$ : $<<0.05$ versus PS I $\leq 7.5$ years old; $\mathrm{d}$ : $\mathrm{p}<0.05$ girls in PS IV-V versus PS I $>7.5$ years old; $\infty: \mathrm{p}<0.01$ versus PS I $\leq 7.5$ years old; $\Omega$ : $\mathrm{p}<0.05$ boys in PS IV-V versus girls in the same PS. 
IR SDSs $(0.5 \pm 1.1$ versus $-0.2 \pm 1.1, p<0.001)$, and lower $G /$ Ins values $(0.0 \pm 0.9$ versus $0.2 \pm 1.2$, $p<0.01)$ compared to Q1.

\section{DISCUSSION}

Indices that use baseline glucose and insulin levels are useful for the early detection of insulin resistance during childhood and to make decisions aimed at reversing the condition. However, in pediatrics, information on the RIs for fasting insulin and insulin sensitivity surrogate indices is scarce. ${ }^{24,25}$ It is worth noting that insulin immunoassay manufacturers recommend a single insulinemia interval obtained in the adult population and fail to indicate a reference interval for children and adolescents. Therefore, we strongly recommend that laboratories specialized in pediatric endocrinology collaborate with establishing insulin RIs for the method they use.

A review made by Ten and MacLaren ${ }^{25}$ defines insulin resistance in children as a baseline serum insulin level $\geq 15 \mu \mathrm{IU} / \mathrm{mL}$, with no differences made in terms of age or PS. An upper value of $9.5 \mu \mathrm{IU} / \mathrm{mL}$ was obtained in prepubertal European children using the same method as in our study. ${ }^{26}$ Our study showed the known insulin variation by BMI, age, PS, IGF-1 level and, to a lesser extent, sex, ${ }^{11,12,21,26,27}$ and this suggests that these outcome measures should be taken into account to define pediatric RIs. Insulin increased at a peripubertal age, and changes in insulin sensitivity were observed before the onset of clinical puberty. Jeffery et al. observed that insulin increased around 7 years old, before the increase in luteinizing hormone (LH) and the onset of clinical signs of puberty. ${ }^{28}$ Increases in adiposity, adrenal androgens, and IGF-1 might explain the lower insulin sensitivity observed before the onset of puberty. In support of these hypotheses, our task force observed that 17-hydroxyprogesterone (an androgen precursor) and IGF-1 levels in healthy peripubertal children were significantly higher than those in younger prepubertal children. ${ }^{21,23}$ During puberty, insulin increased compared to prepuberty levels, accompanied by sexual dimorphism during late puberty. The lower insulin sensitivity observed in prepubertal girls is likely due to a higher GH secretion in pubertal girls, ${ }^{29,30}$ or differences in insulin peripheral action in both boys and girls. ${ }^{13}$ However, in boys after PS V, it has been demonstrated that insulin resistance may increase as well as cardiovascular risk. ${ }^{31}$

The results of our study might have been affected by the change in the method used to measure insulin during the study period. However, the performance of both methods was verified through quality controls, and it has been established that likely deviations between both methods are insignificant for result interpretation. Therefore, we propose that a fasting insulin level $>10 \mu \mathrm{IU} / \mathrm{mL}$ for prepubertal children and of $17 \mu \mathrm{IU} / \mathrm{mL}$ and $13 \mu \mathrm{IU} / \mathrm{mL}$ for pubertal girls and boys, respectively, might serve as a warning sign for pediatricians to investigate potential insulin resistance and further test glucose homeostasis.

Values obtained with surrogate insulin sensitivity indices are strongly influenced by the method used to measure insulin, and differences have been frequently published by different authors, especially in relation to the most widely used index: HOMA-IR. ${ }^{8-13,26,32}$ In this study, indices showed differences in insulin sensitivity with puberty development similar to baseline insulin. Schwartz et al. found a modest correlation between insulin sensitivity surrogates

TABLE 2: Reference intervals for fasting insulin and G/Ins ratio, HOMA-IR index, and QUICKI obtained in 226 healthy children and adolescents

\begin{tabular}{lcccc}
\hline Group & Insulin & G/Ins & HOMA-IR & QUICKI \\
\hline Prepubertal $(\mathbf{n}=\mathbf{1 2 2})$ & $3.5(1.6-10.9)$ & $24(10-50)$ & $0.7(0.3-1.9)$ & $0.40(0.33-0.49)$ \\
$\quad \leq 7.5$ years old & $2.9(1.3-10.9)$ & $29(12-50)$ & $0.6(0.3-1.4)$ & $0.41(0.32-0.50)$ \\
$\quad>7.5$ years old & $5.0(1.7-9.6)$ & $20(10-47)$ & $1.1(0.3-2.0)$ & $0.38(0.34-0.48)$ \\
Pubertal (n= 104) & $7.1(1.9-16.9)$ & $14(7.9-44)$ & $1.4(0.3-2.5)$ & $0.37(0.32-0.47)$ \\
$\quad$ Girls & $6.7(1.8-16.9)$ & $12(7.9-44)$ & $1.6(0.3-2.6)$ & $0.36(0.31-0.47)$ \\
$\quad$ Boys & $7.3(2.2-12.9)$ & $16(8.0-44)$ & $1.1(0.3-2.4)$ & $0.38(0.32-0.47)$ \\
\hline
\end{tabular}

G/Ins: glycemia/insulin ratio; HOMA-IR: homeostasis model assessment of insulin resistance;

QUICKI: quantitative insulin sensitivity check index.

The insulin level $(\mu \mathrm{IU} / \mathrm{mL})$, and the $\mathrm{G} / \mathrm{Ins}$ ratio [G $(\mathrm{mg} / \mathrm{dL})$ and Ins $(\mu \mathrm{IU} / \mathrm{mL})]$, HOMA-IR [Ins $(\mu \mathrm{IU} / \mathrm{mL}) \times \mathrm{G}(\mathrm{mmol} / \mathrm{L}) / 22.5]$, and QUICKI $[1 /(\log \operatorname{Ins}(\mu \mathrm{IU} / \mathrm{mL})+\log \mathrm{G}(\mathrm{mg} / \mathrm{dL})]$ are described as median and percentile range 3-97. 
and reference clamp methods in children and adolescents, and suggested that indices do not provide an additional advantage compared to baseline insulinemia. ${ }^{33}$ Only insulin level and the HOMA-IR index showed changes in insulin sensitivity during prepuberty. Differences during prepuberty and puberty had been previously reported..$^{8,26-28}$ Based on our results, a HOMAIR higher than $1.4,2.0$, and 2.6 in prepubertal children younger and older than 7.5 years old and pubertal children, respectively, and a G/ Ins ratio value below 10 suggest certain level of insulin resistance in children and adolescents. Our study proposes a RI for simplified glycemia and insulinemia indices obtained in fasting conditions; however, there are other indices that reflect insulin sensitivity in baseline conditions and in the post-absorption phase. ${ }^{7}$

Insulin and HOMA-IR SDSs in the upper quartile of triglyceride levels were higher compared to the lower quartile; this indicates that insulin sensitive children have a lower triglyceride level. Defects in free fatty acid esterification and reesterification processes in fat tissue, and a reduced insulin inhibitory action on the hormone-sensitive lipase (responsible for triglyceride lipolysis in adipocytes) are early signs of insulin resistance, which may be detected even before postprandial or fasting hyperglycemia is established. ${ }^{34}$ Therefore, the transient, physiological increase in insulin and insulin resistance during puberty may be promoted in children with a larger visceral fat mass and become a risk factor for dyslipemia, hypertension, and DM2 during adolescence. ${ }^{35}$

\section{CONCLUSION}

This study established RIs for fasting insulin and for the most commonly used surrogate insulin sensitivity and insulin resistance indices. These parameters evidence physiological changes in insulin sensitivity and their association with IGF-1 and triglyceride levels; the latter is the lipid metabolism component most commonly affected in insulin resistance. Fasting insulin and surrogate index RIs obtained in this stage of life can be directly applied by pediatricians, and may warn them of a likely insulin resistance status and of the need to further test glucose homeostasis and lipid profile, especially among obese children and those with a family history of DM2. It is still necessary to assess the diagnostic effectiveness of the proposed indicators for endocrine and nonendocrine conditions associated with glucose metabolism alterations. $\mathrm{n}$

\section{Acknowledgments}

The authors would like to thank health team members: physicians, biochemists, technicians, and nurses from the Department of Endocrinology of Hospital de Niños Dr. Ricardo Gutiérrez. Special thanks to lab technicians Ana María Montese, Mónica Campos, and Silvina González from the Endocrinology Lab of the Department of Endocrinology of Hospital de Niños Dr. Ricardo Gutiérrez) and biochemists María Julieta Gastaldi, and Paula Scaglia, Liliana Karabatas, M.D., and Susana Mancini, B.S., from the Center for Endocrinological Research "Dr. César Bergadá" (CEDIE) and the National Scientific and Technical Research Council (CONICET).

\section{REFERENCES}

1. Organización Mundial de la Salud. Diabetes. Día Programa de la OMS. [Accessed on: August $6^{\text {th }}, 2015$ ]. Available at: http://www.who.int/diabetes/es/.

2. Weyer C, Bogardus C, Mott DM, Pratley RE. The natural history of insulin secretory dysfunction and insulin resistance in the pathogenesis of type 2 diabetes mellitus. J Clin Invest 1999;104(6):787-94.

3. Kelly LA, Lane CJ, Weigensberg MJ, Toledo-Corral CM, et al. Pubertal changes of insulin sensitivity, acute insulin response and -cell function in overweight Latino youth. $J$ Pediatr 2011;158(3):442-6.

4. Arslanian SA. Clamp techniques in paediatrics: what have we learned? Horm Res 2005;64(Suppl 3):16-24.

5. Bergman RN. Minimal model: perspective from 2005. Horm Res 2005;64(Suppl 3):8-15.

6. Zimmet P, Alberti KG, Kaufman F, Tajima N, et al. The metabolic syndrome in children and adolescents - an IDF consensus report. Pediatr Diabetes 2007;8(5):299-306.

7. Matsuda M, DeFronzo RA. Insulin sensitivity indices obtained from oral glucose tolerance testing: comparison with the euglycemic insulin clamp. Diabetes Care 1999;22(9):1462-70.

8. Gungor N, Saad R, Janosky J, Arslanian S. Validation of surrogates estimates of insulin sensitivity and insulin secretion in children and adolescents. J Pediatr 2004;144(1):47-55.

9. Conwell LS, TrostSG, Brown WJ, Batch JA. Indexes of insulin resistance and secretion in obese children and adolescents: a validation study. Diabetes Care 2004;27(2):314-9.

10. Werner M, Tönjes A, Stumvoll M, Thiery J, et al. Assaydependent variability of serum insulin levels during oral glucose tolerance test: influence on reference intervals for insulin and on cut-off values for insulin sensitivity indices. Clin Chem Lab Med 2008;46(2):240-6.

11. Goran MI, Gower BA. Longitudinalstudy on pubertal insulin resistance. Diabetes 2001;50(11):2444-50.

12. Hannon TS, Janosky J, Arslanian SA. Longitudinal study of physiologic insulin resistance and metabolic changes of puberty. Pediatr Res 2006;60(6):759-63.

13. Hoffman RP, Vicini P, Sivitz WI, Cobelli C. Pubertal adolescentmale-female differences in insulin sensitivity and glucose effectiveness determined by the one compartment minimal model. Pediatr Res 2000;48(3):384-8.

14. Vistisen B, Hellgren LI, Vadset T, Scheede-Bergdahl C, et al. Effect of gender on lipid-induced insulin resistance in obese subjects. Eur J Endocrinol 2008;158(1):61-8. 
15. Laakso M, Sarlund H, Mykkänen L. Insulin resistance is associated with lipid and lipoprotein abnormalities in subjects with varying degrees of glucose tolerance. Arteriosclerosis 1990;10(2):223-31.

16. Lejarraga H, del Pino M, Fano V, Caino S, et al. Referencias de peso y estatura desde el nacimiento hasta la madurez para niñas y niños argentinos. Incorporación de datos de la OMS de 0 a 2 años, recálculo de percentilos para obtención de valores LMS. Arch Argent Pediatr 2009;107(2)126-33.

17. Domené HM, Scaglia PA, Martínez AS, Keselman AC, et al. Heterozygous IGFALS gene variants in idiopathic short stature and normal children: impact on height and the IGF system. Horm Res Paediatr 2013;80(6):413-23.

18. Cole TJ,Freeman JV, Preece MA. Body mass index reference curves for the UK, 1990. Arch Dis Child 1995;73(1):25-9.

19. Marshall WA, Tanner JM. Variation in pattern of pubertal changes in girls. Arch Dis Child 1969;44(235):291-303.

20. MarshallWA, TannerJM. Variation in the pattern of pubertal changes in boys. Arch Dis Child 1970;45(239):13-23.

21. Guercio G, Rivarola MA, Chaler E, Maceiras M, et al. Relationship between the growth hormone/insulinlike growth factor-I axis, insulin sensitivity, and adrenalandrogens in normal prepubertal and pubertal girls. J Clin Endocrinol Metab 2003;88(3):1389-93.

22. Ballerini MG, Chiesa A, Morelli C, Frusti M, et al. Serum concentration of 17 -hydroxyprogesterone in children from birth to adolescence. Horm Res Paediatr 2014;81(2):118-25.

23. Ballerini MG, Domené HM, Scaglia P, Martínez A, et al. Association of serum components of the GH-IGFs-IGFBPs system with GHR-exon 3 polymorphism in normal and idiopathic short stature children. Growth Horm IGF Res 2013;23(6):229-36.

24. Mansoub S, Chan MK, Adeli K. Gap analysis of pediatric reference intervals for risk biomarkers of cardiovascular disease and the metabolic syndrome. Clin Biochem 2006;39(6):569-87.

25. Ten S, Maclaren N. Insulin resistance syndrome in children. J Clin Endocrinol Metab 2004;89(6):2526-39.
26. Peplies J, Jiménez-Pavón D, Savva SC, Buck C, et al. Percentiles of fasting serum insulin, glucose, HbA1c and HOMA-IR in pre-pubertal normal weight European children from the IDEFICS cohort. Int J Obes (Lond) 2014;38(Suppl 2):S39-47.

27. Travers SH, Jeffers BW, Bloch CA, Hill JO, et al. Gender and tanner stage differences in body composition and insulin sensitivity in early pubertal children. J Clin Endocrinol Metab 1995;80(1):172-8.

28. Jeffery AN, Metcalf BS, Hosking J, Streeter AJ, et al. Age before stage: insulin resistance rises before the onset of puberty: a 9-year longitudinal study (EarlyBird 26). Diabetes Care 2012;35(3):536-41.

29. Arslanian SA, Heil BV, Becker DJ, Drash AL. Sexual dimorphism in insulin sensitivity in adolescent with insulin dependent diabetes mellitus. JClin Endocrinol Metab 1991;72(4):920-6.

30. Ballerini MG, Ropelato MG, Domené H, Gutierrez M, et al. Effect of IGF-I-ternary complex formation (TCF) on estimates of insulin sensitivity (ISes) in normal children. J Pediatr Endocrinol Metab 2006;19(Suppl 3):1071.

31. Moran A, Jacobs DR Jr, Steinberger J, Steffen LM, et al. Changes in insulin resistance and cardiovascular risk during adolescence: establishment of differential risk in males and females. Circulation 2008;117(18):2361-8.

32. Shashaj B, Luciano R, Contoli B, Morino GS, et al. Reference ranges of HOMA-IR in normal-weight and obese young Caucasians. Acta Diabetol 2015. Epub 2015 Jun 13.

33. Schwartz B, Jacobs DR Jr, Moran A, Steinberger J, et al. Measurement of insulin sensitivity in children: comparison between the euglycemic-hyperinsulinemic clamp and surrogate measures. Diabetes Care 2008;31(4):783-8.

34. Lewis GF, Carpentier A, Adeli K, Giacca A. Disordered fat storage and mobilization in the pathogenesis of insulin resistance and type 2 diabetes. Endocr Rev 2002;23(2):201-29.

35. Goran MI, Bergman RN, Avila Q, Watkins M, etal. Impaired glucose tolerance and reduced -cell function in overweight Latino children with a positive family history for type 2 diabetes. J Clin Endocrinol Metab 2004;89(1):207-12. 